\title{
Distribution System Reconfiguration for Loss Minimization and Voltage Profile Enhancement by using Discrete - Improved Binary Particle Swarm Optimization Algorithm
}

\author{
S.G. Kamble, K. Vadirajacharya, U.V. Patil
}

\begin{abstract}
Distribution system reconfiguration is done by altering the open / close position of two kinds of switches: usually open tie switches and sectionalizing switches usually closed. Its main purpose is restoration of supply via other route to improve reliability, sometimes for load balancing by relieving overloads. Feeder reconfiguration is very good alternative to reduce power losses and improve voltage profile to improve overall performance. Distribution system reconfiguration is a very cost effective way to reduce the distribution system power losses, enhance voltage profile and system reliability. This paper presents application of novel Discrete - improved binary particle swarm optimization (D-IBPSO) algorithm for distribution system reconfiguration for minimization of real power loss and improvement of voltage profile. The algorithm is implemented to a 16-bus, 33-bus system and a 69-bus system considering different loading conditions. The simulation results indicate that the suggested technique can accomplish optimal reconfiguration and significantly reduce power losses on the supply scheme and enhance the voltage profile.
\end{abstract}

Index Terms-D-IBPSO, distribution system optimization, loss minimization, network reconfiguration.

\section{INTRODUCTION}

Electricity is produced, transported and delivered to end customers in an electrical power system. The distribution network receives power from the transmission system and provides low voltage levels to customers. Residential, commercial and industrial are different kinds of consumer-related loads. The load on the power system changes according to consumer requirement throughout the day and is never continuous. Radial and ring main distribution structures are two kinds of distribution network. The feeders emerging from a single substation is the radial distribution structure, whereas the feeders in a circle or ring shape are ring main structure. The major drawback of radial systems is that it cannot feed the load in the event of power supply failure and is therefore less reliable. Each user is delivered power via two feeders or paths in the ring main scheme. This sort of scheme is more reliable and can be readily retained by isolating one segment and linking

Revised Version Manuscript Received on 16 September, 2019.

S.G. Kamble, Dr. BATU, Lonere, Raigad, Maharashtra, India.

(Email: sachinkamble80@ rediffmail.com)

K. Vadirajacharya, Dr., Lonere, Raigad, Maharashtra, India.

(Email: kvadirajacharya@dbatu.ac.in)

U.V. Patil, Government college of Engineering, Karad, Maharashtra, India.

(Email: patil_uv@yahoo.com) supply via another path to the loads. Radial distribution structures are therefore designed with sectionalization and tie switches to enhance reliability so that the structure can be reconfigured. Reconfiguring is the way to change a network framework by changing the position of ON / OFF switches.

\section{RECONFIGURATION OF DISTRIBUTION SYSTEM}

Merlin and Back [1] first revealed the reconfiguration technique to decrease losses in the distribution network Several algorithms have been designed to fix this issue since then. These algorithms are mostly focused on methods, heuristic techniques, meta-heuristic and artificial intelligence. In this study, they suggested a heuristic algorithm to find out the minimum loss configuration of switches (setup) as a mixed non-linear optimization problem. They used a discreet branch and bound method; i.e. first, all switches are closed to establish a meshed network. These switches are then opened consecutively to maintain radial setup. It was suggested by Civanlar et al. [2] and Baran et al. [5] to use other heuristic approaches depending on the method of branch swap to identify the losses. The Merlin and Back technique has been enhanced by Shirmomohammadi and Hong [3]. As a consequence, it has the main advantages of this technique, convergence to the optimum or close optimum alternative, and independence of the final solution from the network switches ' original status. Simultaneously, this technique prevents all of Merlin and Back's significant drawbacks. Goswami and Basu [4] suggested an algorithm focused on the optimum flow structure obtained through a circuit by removing a switch usually accessed by opening a closed switch in the radial distribution system. To minimize the power losses and balance the loads on feeders, Baran and $\mathrm{Wu}$ [5] provided a heuristic reconfiguration technique centered on branch swap. Two approximate load flow techniques for radial structured network with varying degrees of precision are used to help in the search. They are easy technique of power flow and updating the power flow method back and forward. Due to complex arrangements in larger systems and converging to local optimum solutions, the global optimum convergence is not ensured. The technique is very time consuming. Gohokar et al. [6] provided a network 


\section{Distribution System Reconfiguration for Loss Minimization and Voltage Profile Enhancement by using Discrete - Improved Binary Particle Swarm Optimization Algorithm}

structure strategy using one-loop optimization centered on the highest voltage decrease for open switch configuration. Nara et al. [7] introduced the genetic algorithm to reconfigure an AI-based methods-based radial allocation scheme with minimal failure. Lin et al. [8], Zhu [9], Delbem et al. [10], Prasad et al. [11], Mendoza et al. [12], Enacheanu et al. [13] pursue various GA variations and modifications. $\mathrm{Su}$ et al. [14] presented to fix the issue of optimum distribution system reconfiguration to minimize the power loss, the ant colony optimization (ACO) algorithm was implemented. Lin et al. [15] implemented the immune algorithm to reconfigure a radial supply scheme for to reduce the power loss and to balance the load on distribution lines or feeders. Hsiao and Chen [16] implemented a multi-objective distribution system reconfiguration system by using evolutionary programming. Das [ 17 ] proposed an intrusive strategy with a heuristic rules framework for multi-objective feeder reconfiguration. Falaghi et al. [18] presented a methodology to reconfigure the radial distribution system by considering the distributed generation (DG). A fuzzy method is used for multi-objective variables. In order to create a multi-objective fuzzy system for optimal allocation scheme scheduling, the multi-objective tabu search algorithm of Ramirez-Rosado and Dominguez-Navarro [19] was provided. Ahuja et al. [20] suggested an artificial fusion model on the basis of immune system and optimization of ant colony to reconfigure the radial distribution system as a many objective task. In response to the issue of voltage control and energy loss reduction on distribution system, Augugugliaro et al. [21] employed a wide range of goal heuristic optimizations. The Particle Swarm Optimization (PSO) is influenced by a herd of migrating birds social conduct attempting to achieve an unidentified target. Each alternative in PSO is a bird in the herd and is called a particle. A particle is similar to a GAs chromosome. Unlike GAs, the PSO's evolutionary process does not generate fresh parent birds. Instead, the population's birds only develop their social behavior and their motion toward a target appropriately. Each bird appears in a particular direction, and then they recognize the bird in the finest place when they communicate together. Thus, each bird flies towards the finest bird using a speed depending on its present situation. Each bird then explores the search space from its fresh local place and performs the cycle until a required location is reached by the herd. Tamer M. Khalil and Alexander V. Gorpinich [22] used for loss minimization selective particle swarm optimization (SPSO). The binary particle swarm Optimization (BPSO) algorithm is a simple amendment. The algorithm's search space is a collection of branches (switches) that are usually closed or opened, search space can be different for distinct sizes. The reconfiguration issue solving method is organized into two phases. First, discover search area after all the switches are closed and then, use SPSO to locate open switches. The method described is implemented to a scheme with 33 buses and a scheme with 69 buses. To show the performance of the suggested algorithm, the outcomes acquired through SPSO are contrasted with some prior techniques.

The PSO search procedure depends on the past best particle solution and the best solution for updating particle data in the population. This implies that the particles share the best data and guide the particles towards the goal. Due to the
PSO-designed search system, the probability of dropping into a local PSO algorithm alternative may be decreased. The PSO algorithm is easy and simple to execute. PSO can thus be a strong tool for helping and speeding up the decision-making method in finding the appropriate schedule for distribution system reconfiguration.

Problems with distribution system reconfiguration are non-linear problems with discrete optimization. However, the typical PSO is designed for continuous feature optimization issues; it isn't designed for discreet function optimisation problems.

While the BPSO solution to the discreet optimization problems can be used, problems persist when the BPSO application is applied to distribution system reconfiguration problems. There are number of tie-switches in the distribution system reconfiguration issues. In distribution systems, selecting randomly the locations of these tie-switches may possibly result in non-supply to some of the loads and or non-radial structure. Chang et al. [23], BPSO is presented to resolve the problem of distribution system reconfiguration and the method proposed prevented the problem of inappropriate tie-switch numbers.

This wok proposes a more practicable discrete - improved binary PSO algorithm from typical PSO for distribution system reconfiguration instead of the BPSO used in [23]. This study has modified the technique suggested to make binary particle swarm optimisation for reconfiguration of distribution system depending on the features of the switch position and the shifting operator.

\section{MATHEMATICAL MODELLING}

As stated in equation (1), the power loss reduction problem is expressed mathematically.

$$
P_{\text {loss }}=\sum_{l=1}^{N L} k_{l} R_{j k}\left(\frac{P_{j}^{2}+Q_{j}^{2}}{V_{j}^{2}}\right)
$$

\section{Where,}

$l$ is the $j-k$ lines branch number.

$V j$ is $j_{\text {th }}$ node voltage.

$P j$ and $Q j$ are the real and the reactive power flow in branch $l$

$k l$ is the status of the branches.

$k l=1$ if branch $l$ is closed and

$k l=0$ if the branch is open.

$N L$ is the number of branches in the system.

The preceding limits are imposed on the designed distribution system reconfiguration algorithm.

\section{a. Current limit for branch}

In any branch $l$, the current should be less than the rated branch current.

This is articulated and provided mathematically in Equation (2).

$$
\left|I_{l}\right| \leq I_{l \max } l \in N L
$$




\section{b. Voltage limits for bus}

The voltage at each node $i$ should be within the suggested limit. This is developed and presented in equation mathematically (3).

$\mathbf{V}_{\text {imin }} \leq \mathbf{V i} \leq \mathbf{V}_{\text {imax }} \mathbf{i} \in \mathbf{N}$

\section{c. Topological limitations}

The topological limitation is to guarantee that the distribution network is radially arranged.

- If the allocation scheme does not have separate nodes, the topological constraint will be encountered.

- No closed loops are available in the distribution system, i.e. radial distribution system structure.

\section{DISCRETE - IMPROVED BINARY PARTICLE SWARM OPTIMIZATION (D-IBPSO)}

In 1995, Eberhart and Kennedy developed the methodology of Particle Swarm Optimization (PSO). It is an algorithm of stochastic search influenced by flocking birds or social behavior in fish education. The PSO starts with a random-positioned search space population of particles. Each particle is a fitness-value problem-solving alternative. It will evaluate and optimize the fitness. Defines a speed that iteration. Because of their optimal place and the greatest alternative that teams have ever encountered, particles are progressively moving towards the ideal solution. Furthermore, a restricted number of parameters must be adapted and a restricted reliance on the original values. The main advantage of the PSO is that it has to deal with a few parameters. Some of the PSO algorithm's parameters include particle size, search space size, particle size, termination criterion, and acceleration training factors or coefficients.

\section{D-IBPSO algorithm for the distribution system reconfiguration}

The D-IBPSO algorithm is created to reduce the actual energy loss in distribution schemes by reconfiguring the distribution system feeder. Using the following procedure, the D-IBPSO algorithm is implemented:

Step 1: Initialization of the parameters

Read the distribution scheme information. Initialize the parameters for the binary D-IBPSO. Initialize the location of the particles. Use the equation (4) to initialize the particle velocity.

$$
\operatorname{velocity}(\mathbf{i}, \mathbf{j})=\mathbf{v}_{\text {min }}+\left(\mathbf{v}_{\text {max }}-\mathbf{v}_{\text {min }}\right) * \text { rand }
$$

Step 2: Find the personal best position of the each particle. In this situation, the original location of particles is presumed to be the best place of particles. Then run the load flow depending on the personal best place of the particles and calculate the power loss.

Step 3: Discover the best global particle location provided in Step 2 from the best particle location set. In this scenario particle location with lowest power loss is the best global particle location.

Step 4: Calculate the distribution networks bus incidence matrix. This assists to find whether or not the structure of the network is radial. Initiate the method of binary D-IBPSO iteration and put the counter to 1 . enables each particle's location and is changed in each

Step 5: Check the limitations of the topology. This phase guarantees that only viable distribution network topologies evaluate the power loss.

Step 6: Use the Newton-Raphson method to calculate the power loss in the given system.

Step 7: Revise the particles ' personal best using equation (5).

$$
\text { Pbest }_{i}^{t+1}=\left\{\begin{array}{c}
\text { Pbest }_{i}^{t+1} \\
X i_{i}^{t+1}
\end{array} \text { if } \text { fitness }_{i}^{t+1} \geq\right.
$$

\section{fitness Pbest $t_{i}^{t}$}

otherwise

Step 8: Revise the global best of the particle herd using equation (6).

$$
\begin{aligned}
& \text { Gbest }^{t+1}=\left\{\begin{array}{c}
\text { Gbest }^{t} \\
\text { Pbest }_{i}^{t+1}
\end{array} \text { if } \text { fitness }_{\text {Pbest }_{i}}^{t+1} \geq\right. \\
& \text { fitness }_{\text {Gbest }}^{t} \\
& \text { otherwise }
\end{aligned}
$$

Step 9: Determine the weight of inertia and update the speed of all particles with the help of equation (7).

$$
\omega=\omega_{\max }-\left(\frac{\omega_{\max }-\omega_{\max }}{t_{\max }}\right) * \mathrm{t}
$$

Step 10: Update the position of the particles by using equation (8).

$$
\begin{aligned}
\mathbf{x i}^{\mathbf{k}}= & \{\mathbf{1} \mathbf{i f r}<\operatorname{sig}(\mathbf{v i k}) \\
& \left\{\mathbf{0 i f r} \mathbf{r} \geq \operatorname{sig}\left(\mathbf{v i} \mathbf{i}^{\mathbf{k}}\right)\right.
\end{aligned}
$$

Step 11: Increase count of the iteration for D-IBPSO search method and repeat step 5 to step 10 until the termination criterion has been reached.

Step 12: Output the search outcomes like best global alternative (ideal network structure), its respective fitness score (minimal energy loss) and the D-IBPSO algorithm's convergence rate.

\section{IMPLEMENTATION OF D-IBPSO ALGORITHM FOR THE DISTRIBUTION SYSTEM RECONFIGURATION}

Three distribution systems of IEEE 16, 33 and 69 bus are used to assess the performance and effectiveness of the D-IBPSO algorithm. The assessment is done on the basis of power loss, voltage magnitude at bus and the topology of the distribution system. Comparison with the literature results is made for the suggested D-IBPSO algorithm.

The developed binary D-IBPSO algorithm's predefined parameters are as shown below.

\section{D-IBPSO parameters}

$W_{\min }=0.4, W_{\max }=0.9$, Coefficient of acceleration $(\mathrm{c} 1$ and c2) $=2$, Maximum speed or velocity $V_{\max }=4$

\section{Case Study 1: IEEE 16 bus system}

The 16-bus distribution scheme is a radial distribution network of $12.66 \mathrm{kV}$, with base MVA 100 . It comprises of three primary feeders, 13 set loads, seven shunt condensers, and 16 branches. Out of 16 branches 13 are sectionalizers, and three are tie lines. The complete actual power demands and reactive power requirements are $28700 \mathrm{~kW}$ and 17300 $\mathrm{kVAR}$ respectively. The technique of Newton-Raphson

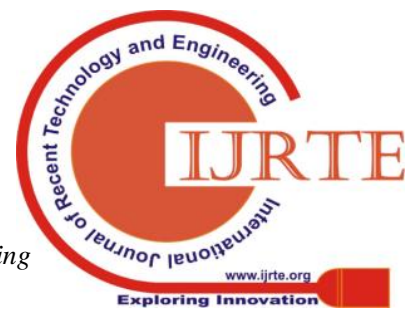


Distribution System Reconfiguration for Loss Minimization and Voltage Profile Enhancement by using Discrete Improved Binary Particle Swarm Optimization Algorithm

calculates the outcomes of the load flow in the MATLAB.

Table 1 provides a comparison of the outcomes of the 16-bus distribution scheme with the D-IBPSO algorithm before and after feeder reconfiguration. Figure 1 provides the voltage profile in the distribution scheme.

Table 1: Results of the 16 bus system

\begin{tabular}{|c|c|c|}
\hline Results & $\begin{array}{c}\text { Base } \\
\text { Reconfiguration }\end{array}$ & $\begin{array}{c}\text { Optimal } \\
\text { Reconfiguration }\end{array}$ \\
\hline $\begin{array}{c}\text { Open } \\
\text { switches }\end{array}$ & $14,15,16$ & $7,8,16$ \\
\hline $\mathbf{P}_{\text {LOSS }}$ (kW) & 514.02 & 468.33 \\
\hline $\begin{array}{c}\text { \% } \mathbf{P}_{\text {LOSS }} \\
\text { reduction }\end{array}$ & - & 8.89 \\
\hline Vmin (p.u.) & 0.968 & 0.970 \\
\hline
\end{tabular}

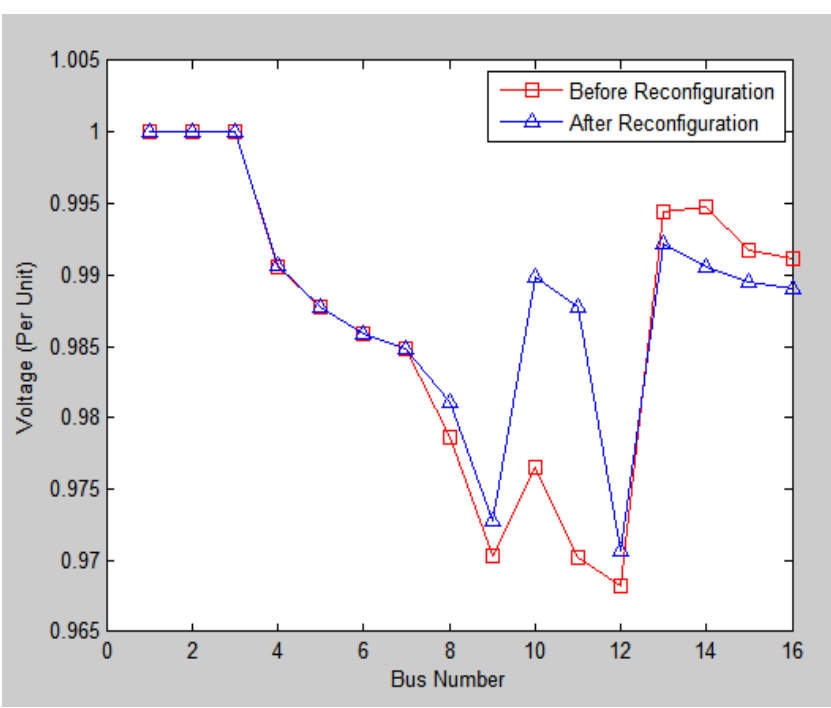

Figure 1: Voltage magnitude for the 16 bus system

Table 2: Results for the D-IBPSO compared with other algorithms for 16 bus system

\begin{tabular}{|c|c|c|c|c|c|}
\hline \multicolumn{2}{|c|}{ Algorithm used } & \multirow{2}{*}{$\begin{array}{l}\begin{array}{l}\text { D-IBPSO } \\
\text { proposed }\end{array} \\
14,15,16\end{array}$} & \multirow{2}{*}{$\begin{array}{c}\text { Refined } \\
\text { GA [24] } \\
\\
14,15, \\
16\end{array}$} & \multirow{2}{*}{$\begin{array}{c}\text { ACO } \\
{[25]} \\
14,15, \\
16\end{array}$} & \multirow{2}{*}{$\begin{array}{c}\text { SEM } \\
\text { [26] } \\
14,15,16\end{array}$} \\
\hline & $\begin{array}{l}\text { Open } \\
\text { switches }\end{array}$ & & & & \\
\hline Reconfiguration & $\begin{array}{l}\mathbf{P}_{\text {LOSS }} \\
(\mathbf{k W})\end{array}$ & 514.02 & 511.4 & 511.4 & - \\
\hline \multirow{3}{*}{$\begin{array}{l}\text { Optimal } \\
\text { Reconfiguration }\end{array}$} & $\begin{array}{l}\text { Open } \\
\text { switches }\end{array}$ & $7,8,16$ & $7,8,16$ & $7,8,16$ & $7,8,16$ \\
\hline & $\begin{array}{l}\mathbf{P}_{\text {LOSS }} \\
(\mathbf{k W})\end{array}$ & 468.33 & 466.1 & 466.1 & 466.13 \\
\hline & $\begin{array}{l}\% \quad \mathbf{P}_{\text {Loss }} \\
\text { reduction }\end{array}$ & 8.89 & 8.85 & 8.85 & - \\
\hline
\end{tabular}

Table 3: Results of the D-IBPSO for the 16 bus system at various load conditions

\begin{tabular}{|c|c|c|c|c|c|}
\hline \multicolumn{2}{|c|}{$\%$ Load } & $\mathbf{5 0 \%}$ & $75 \%$ & $100 \%$ & $125 \%$ \\
\hline \multirow{3}{*}{$\begin{array}{c}\text { Base } \\
\text { Reconfigura } \\
\text { tion }\end{array}$} & $\begin{array}{l}\text { Open } \\
\text { switches }\end{array}$ & $\begin{array}{c}14,15, \\
16\end{array}$ & $\begin{array}{c}14,15 \\
16\end{array}$ & $\begin{array}{c}14,15 \\
16\end{array}$ & $\begin{array}{c}14,15 \\
16\end{array}$ \\
\hline & $\mathbf{P}_{\text {LOSS }}(\mathbf{k W})$ & 139.10 & $\begin{array}{c}282.0 \\
9 \\
\end{array}$ & $\begin{array}{c}514.0 \\
2 \\
\end{array}$ & 838.49 \\
\hline & $\begin{array}{c}\text { Minimum } \\
\text { voltage } \\
\text { (p.u.) }\end{array}$ & 0.991 & 0.980 & 0.968 & 0.955 \\
\hline \multirow{4}{*}{$\begin{array}{c}\text { Optimal } \\
\text { Reconfigura } \\
\text { tion }\end{array}$} & $\begin{array}{l}\text { Open } \\
\text { switches }\end{array}$ & $7,8,16$ & $7,8,16$ & $7,8,16$ & $7,8,16$ \\
\hline & $\begin{array}{c}\text { Power loss } \\
(\mathrm{kW})\end{array}$ & 125.14 & $\begin{array}{c}256.0 \\
3 \\
\end{array}$ & $\begin{array}{c}468.3 \\
3 \\
\end{array}$ & 764.66 \\
\hline & $\begin{array}{l}\text { Vmin } \\
\text { (p.u.) }\end{array}$ & 0.992 & 0.982 & 0.971 & 0.959 \\
\hline & $\begin{array}{c}\% \mathbf{P}_{\text {Loss }} \\
\text { reduction }\end{array}$ & 10.03 & 9.23 & 8.89 & 8.81 \\
\hline
\end{tabular}

Case Study 2: IEEE 33 bus system

Table 4: Results of the 33 bus system

\begin{tabular}{|l|c|c|}
\hline \multicolumn{1}{|c|}{ Results } & $\begin{array}{c}\text { Base } \\
\text { Reconfiguration }\end{array}$ & $\begin{array}{c}\text { Optimal } \\
\text { Reconfiguration }\end{array}$ \\
\hline Open switches & $33,34,35,36,37$ & $7,9,14,32,37$ \\
\hline $\mathbf{P}_{\text {LOSS }}(\mathbf{k W})$ & 208.43 & 138.92 \\
\hline $\begin{array}{l}\text { \% } \mathbf{P}_{\text {LOSS }} \\
\text { reduction }\end{array}$ & - & 33.35 \\
\hline Vmin (p.u.) & 0.910 & 0.942 \\
\hline
\end{tabular}

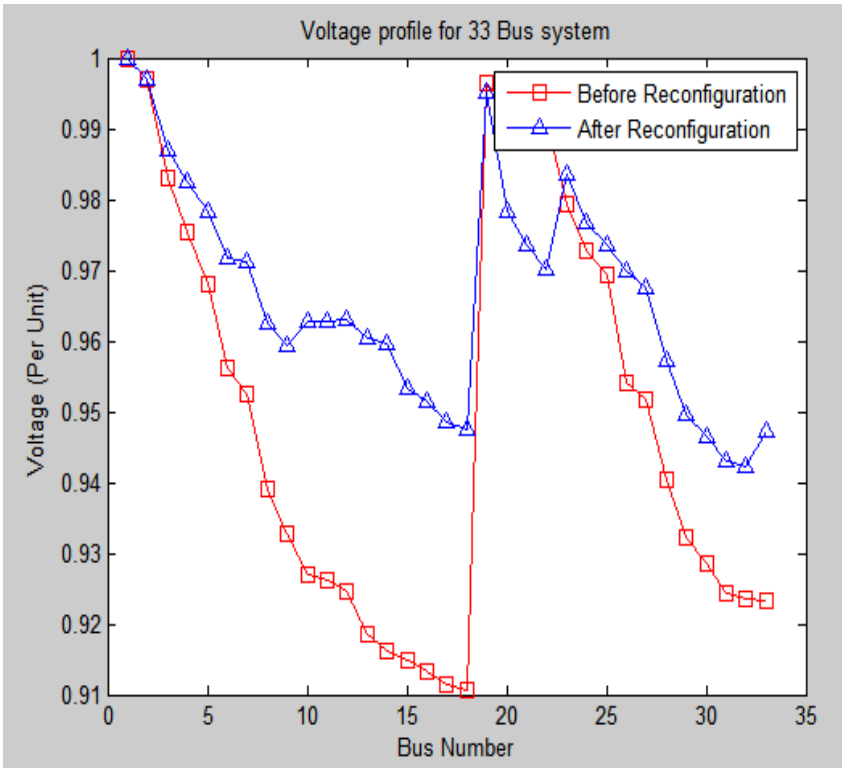

Figure 2: Voltage magnitude for the 33 bus system 
Table 5: Results for the D-IBPSO compared with other algorithms for 33 bus system

\begin{tabular}{|c|c|c|c|c|}
\hline \multicolumn{2}{|c|}{ Algorithm used } & \multirow{2}{*}{$\begin{array}{c}\begin{array}{c}\text { D-IBPSO } \\
\text { proposed }\end{array} \\
33,34,35, \\
36,37\end{array}$} & \multirow{2}{*}{$\begin{array}{c}\text { SSOM [27] } \\
\begin{array}{c}33,34,35, \\
36,37\end{array}\end{array}$} & \multirow{2}{*}{$\begin{array}{c}\begin{array}{c}\text { Hybrid } \\
\text { PSO [28] }\end{array} \\
33,34,35, \\
36,37\end{array}$} \\
\hline \multirow{3}{*}{$\begin{array}{l}\text { Base } \\
\text { Reconfigur } \\
\text { ation }\end{array}$} & $\begin{array}{l}\text { Open } \\
\text { switches }\end{array}$ & & & \\
\hline & $\begin{array}{l}\mathbf{P}_{\text {LOSS }} \\
(\mathbf{k W})\end{array}$ & 208.43 & 202.05 & 202.67 \\
\hline & $\begin{array}{l}\text { Vmin } \\
\text { (p.u.) }\end{array}$ & 0.910 & 0.913 & 0.913 \\
\hline \multirow{4}{*}{$\begin{array}{l}\text { Optimal } \\
\text { Reconfigur } \\
\text { ation }\end{array}$} & $\begin{array}{l}\text { Open } \\
\text { switches }\end{array}$ & $\begin{array}{c}7,9,14,32, \\
37\end{array}$ & $\begin{array}{c}7,9,14,32, \\
37\end{array}$ & $\begin{array}{c}7,9,14 \\
32,37\end{array}$ \\
\hline & $\begin{array}{l}\mathbf{P}_{\text {LOSS }} \\
(\mathbf{k W})\end{array}$ & 138.92 & 139.21 & 139.53 \\
\hline & $\begin{array}{l}\text { Vmin } \\
\text { (p.u.) }\end{array}$ & 0.942 & 0.937 & 0.938 \\
\hline & $\begin{array}{l}\% \quad \mathbf{P}_{\text {Loss }} \\
\text { reduction }\end{array}$ & 33.35 & 31.10 & 31.14 \\
\hline
\end{tabular}

Table 6: Results of the D-IBPSO for the 33 bus system at various load conditions

\begin{tabular}{|c|c|c|c|c|c|}
\hline \multicolumn{2}{|c|}{$\%$ Load } & $50 \%$ & $75 \%$ & $100 \%$ & $125 \%$ \\
\hline \multirow{3}{*}{$\begin{array}{c}\text { Base } \\
\text { Reconfi } \\
\text { guration }\end{array}$} & $\begin{array}{c}\text { Open } \\
\text { switches }\end{array}$ & $\begin{array}{c}33,34 \\
35,36 \\
37\end{array}$ & $\begin{array}{c}33,34 \\
35,36 \\
37\end{array}$ & $\begin{array}{c}33,34 \\
35,36 \\
37\end{array}$ & $\begin{array}{c}33,34 \\
35,36 \\
37\end{array}$ \\
\hline & $\begin{array}{l}\mathbf{P}_{\text {LoSS }} \\
(\mathrm{kW})\end{array}$ & 49.08 & 113.01 & 208.45 & 338.72 \\
\hline & $\begin{array}{l}\text { Vmin } \\
\text { (p.u.) }\end{array}$ & 0.957 & 0.934 & 0.910 & 0.885 \\
\hline \multirow{4}{*}{$\begin{array}{l}\text { Optimal } \\
\text { Reconfi } \\
\text { guration }\end{array}$} & $\begin{array}{c}\text { Open } \\
\text { switches }\end{array}$ & $\begin{array}{c}7,9,14, \\
32,37\end{array}$ & $\begin{array}{c}7,9,14, \\
32,37\end{array}$ & $\begin{array}{c}7,9,14 \\
32,37\end{array}$ & $\begin{array}{c}7,9,14, \\
32,37\end{array}$ \\
\hline & $\begin{array}{l}\mathbf{P}_{\text {LOSS }} \\
(\mathbf{k W})\end{array}$ & 33.59 & 76.36 & 138.92 & 222.31 \\
\hline & $\begin{array}{l}\text { Vmin } \\
\text { (p.u.) }\end{array}$ & 0.971 & 0.957 & 0.942 & 0.926 \\
\hline & $\begin{array}{l}\% \mathbf{P}_{\text {LOSS }} \\
\text { reductio } \\
\mathbf{n}\end{array}$ & 31.55 & 32.42 & 33.35 & 34.36 \\
\hline
\end{tabular}

Case Study 3: IEEE 69 bus system

Table 7: Results of the 33 bus system

\begin{tabular}{|l|c|c|}
\hline \multicolumn{1}{|c|}{ Results } & $\begin{array}{c}\text { Base } \\
\text { Reconfiguration }\end{array}$ & $\begin{array}{c}\text { Optimal } \\
\text { Reconfiguration }\end{array}$ \\
\hline Open switches & $69,70,71,72,73$ & $14,56,61,69,70$ \\
\hline $\mathbf{P}_{\text {LOSS }}(\mathbf{k W})$ & 224.98 & 98.59 \\
\hline $\begin{array}{l}\text { \% } \mathbf{P}_{\text {LOSS }} \\
\text { reduction }\end{array}$ & - & 56.14 \\
\hline Vmin (p.u.) & 0.909 & 0.949 \\
\hline
\end{tabular}

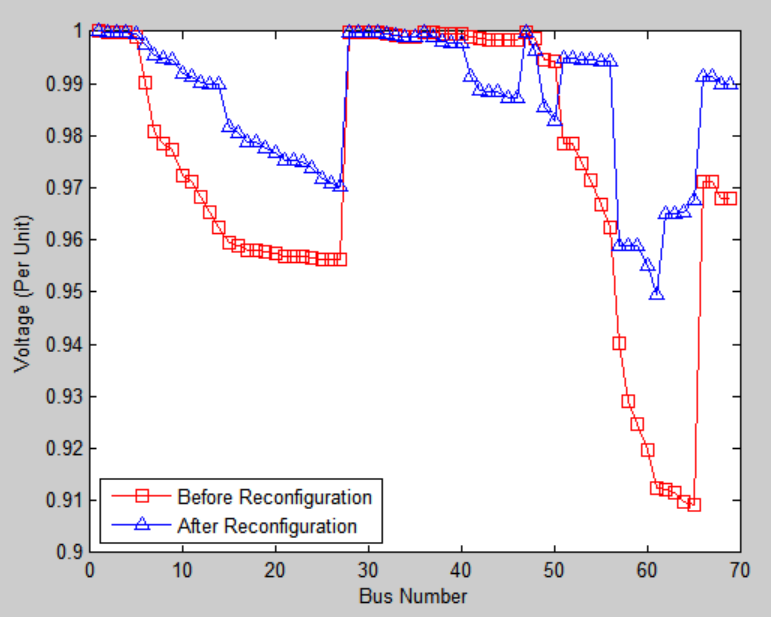

Figure 3: Voltage profile of the 69-bus system

Table 8: Results for the D-IBPSO compared with other algorithms for 69 bus system

\begin{tabular}{|l|l|l|l|l|}
\hline \multicolumn{2}{|c|}{ Algorithm used } & $\begin{array}{l}\text { D-IBPSO } \\
\text { proposed }\end{array}$ & $\begin{array}{l}\text { Fuzzy } \\
\text { multi-objecti } \\
\text { ve approach } \\
{[29]}\end{array}$ & HAS [30] \\
\hline \multirow{3}{*}{$\begin{array}{l}\text { Base } \\
\text { Reconfigur } \\
\text { ation }\end{array}$} & $\begin{array}{l}\text { Open } \\
\text { switches }\end{array}$ & $\begin{array}{c}69,70,71,72 \\
, 73\end{array}$ & $\begin{array}{c}69,70,71,72 \\
, 73\end{array}$ & $\begin{array}{c}69,70,71,72 \\
, 73\end{array}$ \\
\cline { 2 - 6 } & PLOSS (kW) $^{*}$ & 224.98 & 224.95 & 225 \\
\cline { 2 - 6 } & Vmin (p.u.) & $0.909(65)$ & $0.909(65)$ & $0.909(65)$ \\
\hline \multirow{3}{*}{$\begin{array}{l}\text { Optimal } \\
\text { Reconfigur } \\
\text { ation }\end{array}$} & $\begin{array}{l}\text { Open } \\
\text { switches }\end{array}$ & $\begin{array}{c}14,56,61,69 \\
, 70\end{array}$ & $\begin{array}{c}14,56,61,69 \\
, 70\end{array}$ & $\begin{array}{c}14,56,61,69 \\
70\end{array}$ \\
\cline { 2 - 6 } & $\mathbf{P}_{\text {LOSS }}$ (kW) & 98.59 & 99.59 & 99.35 \\
\cline { 2 - 6 } & Vmin (p.u.) & $0.949(61)$ & $0.948(63)$ & $0.942(63)$ \\
\cline { 2 - 6 } & $\begin{array}{l}\text { \% } \\
\text { reduction }\end{array}$ & 56.14 & 55.72 & 55.85 \\
\hline
\end{tabular}

Table 9: Results of the D-IBPSO for the 69 bus system at various load conditions

\begin{tabular}{|c|c|c|c|c|c|}
\hline \multicolumn{2}{|c|}{ \% Load } & $50 \%$ & $75 \%$ & $100 \%$ & $125 \%$ \\
\hline \multirow{3}{*}{$\begin{array}{c}\text { Base } \\
\text { Reconfigu } \\
\text { ration }\end{array}$} & $\begin{array}{c}\text { Tie } \\
\text { switches }\end{array}$ & $\begin{array}{c}69,70,71,7 \\
2,73\end{array}$ & $\begin{array}{c}69,70,71,7 \\
2,73\end{array}$ & $\begin{array}{c}69,70,71,7 \\
2,73\end{array}$ & $\begin{array}{c}69,70,71,7 \\
2,73\end{array}$ \\
\hline & $\begin{array}{c}\text { Power loss } \\
(\mathrm{kW})\end{array}$ & 51.60 & 121.01 & 224.98 & 369.02 \\
\hline & $\begin{array}{c}\text { Minimum } \\
\text { voltage } \\
\text { (p.u.) }\end{array}$ & 0.956 & 0.933 & 0.909 & 0.883 \\
\hline \multirow{4}{*}{$\begin{array}{l}\text { Optimal } \\
\text { Reconfigu } \\
\text { ration }\end{array}$} & $\begin{array}{c}\text { Tie } \\
\text { switches }\end{array}$ & $\begin{array}{c}14,58,61,6 \\
9,7\end{array}$ & $\begin{array}{c}14,58,61,6 \\
9,7\end{array}$ & $\begin{array}{c}14,58,61,6 \\
9,7\end{array}$ & $\begin{array}{c}14,58,61,6 \\
9,7\end{array}$ \\
\hline & $\begin{array}{c}\text { Power loss } \\
(\mathbf{k W})\end{array}$ & 23.60 & 54.25 & 98.59 & 157.61 \\
\hline & $\begin{array}{c}\text { Minimum } \\
\text { voltage } \\
\text { (p.u.) }\end{array}$ & 0.975 & 0.962 & 0.949 & 0.936 \\
\hline & $\begin{array}{c}\text { Power loss } \\
\text { reduction } \\
(\%)\end{array}$ & 54.24 & 55.16 & 56.17 & 57.28 \\
\hline
\end{tabular}

Published By:

Blue Eyes Intelligence Engineering

\& Sciences Publication 


\section{Distribution System Reconfiguration for Loss Minimization and Voltage Profile Enhancement by using Discrete - Improved Binary Particle Swarm Optimization Algorithm}

\section{RESULTS}

D-IBPSO optimization algorithm has been developed in this paper to solve the problem of reconfiguration of the distribution scheme. The problem of distribution system reconfiguration was intended at minimizing the energy loss in distribution systems. To check the performance and effectiveness of the designed D-IBPSO algorithm, the IEEE 16, 33, and 69 bus distribution systems were used. The simulation outcome reveals that the D-IBPSO algorithm created is effective in addressing the issue of reconfiguration. As the load on the power system is variable, the losses and ideal solution for different load circumstances are also found.

Results following the comparison research verify that the D-IBPSO algorithm developed is consistent with the literature techniques present. For the 16 bus system, the reduced losses are close to $9 \%$. The voltage is increased from 0.968 to 0.970 p.u. after reconfiguration of the distribution system. The losses are decreased for different operating (loading) circumstances in the case of 33 bus system after reconfiguration nearly 32 to $34 \%$. Voltage is increased from 0.910 to 0.942 p.u. after reconfiguration.

The power losses for 69 bus scheme are reduced by 55 to $56 \%$ relative to the original setup with variation in loading conditions and the voltage profile is enhanced from 0.909 to 0.949 .

\section{REFERENCES}

1. Merlin, A., and Back, H., "Search for a minimum-loss operating spanning tree configuration in an urban power distribution," Proceedings of the 5th Power System Computation Conference, pp. 1-18, Cambridge, UK, 1975.

2. Civanlar, S., Grainger, J. J., Yin, H., and Lee, S. S. H., "Distribution feeder reconfiguration for loss reduction," IEEE Trans. Power Delivery, Vol. 3, No. 3, pp. 1217-1223, 1988.

3. Shirmohammadi, D., and Hong, W. H., "Reconfiguration of electric distribution networks for resistive line loss reduction," IEEE Trans. Power Delivery, Vol. 4, No. 1, pp. 1492-1498, 1989.

4. Goswami, S. K., and Basu, S. K., "A new algorithm for the reconfiguration of distribution feeders for loss minimization," IEEE Trans. Power Delivery, Vol. 7, No. 3, pp. 1482-1491, 1992.

5. Baran, M. E., and Wu, F. F., "Network reconfiguration in distribution systems for loss reduction and load balancing," IEEE Trans. Power Delivery, Vol. 4, No. 2, pp. 1401-1407, 1989.

6. Gohokar, V. N., Khedkar,M. K., and Dhole, G. M., "Formulation of distribution reconfiguration problem using network topology: A generalized approach," Elect. Power Syst. Res., Vol. 69, No. 2, pp. 304-310, May 2004.

7. Nara, K., Shiose, A., Kiagawa, M., and Ishihara, T., "Implementation of genetic algorithm for distribution system loss minimum reconfiguration," IEEE Trans. Power Syst., Vol. 7, No. 3, pp. 1044-1051, 1992.

8. Lin, M., Cheng, F. S., and Tsay,M. T., "Distribution feeder reconfiguration with refined genetic algorithm," IEE Proc. Generat. Transm. Distribut., Vol. 147, pp. 349-354, 2000.

9. Zhu, J. Z., "Optimal reconfiguration of electric distribution network using refined genetic algorithm," Elect. Power Syst. Res., Vol. 62, pp. 37-42, 2002.

10. Delbem, A. C. B., de Carvalho, A. C. P. D. L. F., and Bretas, N. G., "Main chain representation of evolutionary algorithms applied to distribution system reconfiguration," IEEE Trans. Power Syst., Vol. 20, No. 1, pp. 425-436, 2005.

11. Prasad, K., Ranjan, R., Sahoo, N. C., and Chaturvedi, A., "Optimal configuration of radial distribution system using fuzzy mutated genetic algorithm," IEEE Trans. Power Delivery, Vol. 20, No. 2, pp. 1211-1213, 2005.

12. Mendoza, J., Lopez, R., Morales, D., Lopez, E., Dessante, P., and Moraga, R., "Minimal loss reconfiguration using genetic algorithms with restricted population and addressed operators: Real application," IEEE Trans. Power Syst., Vol. 21, No. 2, pp. 948-954, May 2006.

13. Enacheanu, B., Raison, B., Caire, R., Devaux, O., Bienia, W., and HadjSaid, N., "Radial network reconfiguration using genetic algorithm based on the matroid theory," IEEE Trans. Power Syst., Vol. 23, No. 1, pp. 186-195, February 2008.

14. Su, C. T., Chang, C. F., and Chiou, J. P., "Distribution network reconfiguration for loss reduction by ant colony search algorithm," Elect. Power Syst. Res., Vol. 75, pp. 190-199, May 2005.

15. Lin, C. H., Chen, C. S., Wu, C. J, and Kang, M. S., "Application of immune algorithm to optimal switching operation for distribution loss minimization and load balance," IEE Proc. Generat. Transm. Distribut., Vol. 150, No. 2, pp. 183-189, 2003.

16. Hsiao, Y. J., and Chen, C. Y., "Multi objective feeder reconfiguration," IEE Proc. Generat. Transm. Distribut., Vol. 148, pp. 333-336, 2001.

17. Das, D., "A fuzzy multiobjective approach for network reconfiguration of distribution systems," IEEE Trans. Power Delivery, Vol. 21, No. 1, pp. 202-209, 2006.

18. Falaghi, H., Haghifam, M. R., and Singh, C., "Ant colony optimization-based method for placement of sectionalizing switches in distribution networks using a fuzzy multiobjective approach," IEEE Trans. Power Delivery, Vol. 24, No. 1, pp. 268-276, January 2009.

19. Ramirez-Rosado, I. J., and Dominguez-Navarro, J. A., "New multiobjectivetabu search algorithm for fuzzy optimal planning of power distribution systems," IEEE Trans. Power Syst., Vol. 21, No. 1, pp. 224-233, February 2006.

20. Ahuja, A., Das, S., and Pahwa, A., "An AIS-ACO hybrid approach for multiobjective distribution system reconfiguration," IEEE Trans. Power Syst., Vol. 22, No. 3, pp. 1101-1111, August 2007.

21. Augugliaro, A., Dusonchet, L., Favuzza, S., and Sanseverino, E. R., "Voltage regulation and power losses minimization in automated distribution networks by an evolutionary multiobjective approach," IEEE Trans. Power Syst., Vol. 19, No. 3, pp. 1516-1527, August 2004

22. Tamer M. Khalil, and Alexander V. Gorpinich, "Reconfiguration for Loss Reduction of Distribution Systems Using Selective Particle Swarm Optimization" International Journal Of Multidisciplinary Sciences And Engineering, Vol. 3, No. 6, June 2012.

23. Chang R.F. and Lu C.N., "Feeder Reconfiguration for Load Factor Improvement", IEEE Power Engineering Society Winter Meeting, Vol. 2, 27-31 Jan. 2002, pp.980-984.

24. J. Z. Zhu, "Optimal reconfiguration of electrical distribution network using the refined genetic algorithm", Electr. Power Syst. Res., vol. 62, no. 1, pp. 37-42, May 2002. 
25. Chiou, J., Chang, C. \& Su, C. 2005, "Distribution network reconfiguration for loss reduction by ant colony search algorithm", Electric Power Systems Research, Vol 75(2-3): pp. $190-199$.

26. Gomes, F., Carneiro, S., Pereira, J., Vinagre, M., Garcia, P. \&Araujo, L. 2005, "A New Heuristic Reconfiguration Algorithm for Large Distribution Systems", IEEE Transactions on Power Systems, Vol 20(3): pp. 1373 1378.

27. Afsari, M., Rao, G., Raju, G. \& Singh, S. 2009, "A heuristic method for feeder reconfiguration and service restoration in distribution networks:, International Journal of Electrical Power \& Energy Systems, Vol 31(7-8): pp. $309-314$.

28. Niknam, T., "An efficient hybrid evolutionary algorithm based on PSO and HBMO algorithms for multi-objective Distribution Feeder Reconfiguration”, Energy Conversion and Management, Vol 50(8): pp. 2074 - 2082, 2009.

29. Savier, J. \& Das, D. , "Impact of Network Reconfiguration on Loss Allocation of Radial Distribution Systems", IEEE Transactions on Power Delivery, Vol 22(4): pp. 2473 2480, 2007.

30. Rao, R., Ravindra, K., Satish, K. \&Narasimham, S., "Power Loss Minimization in Distribution System Using Network Reconfiguration in the Presence of Distributed Generation", IEEE Transactions on Power Systems, Vol 28(1): pp. 317 - 325, 2013. 